\title{
The Use of Locked Nails in the Treatment of Humeral Shaft: Delayed Union and Nonunion
}

\author{
Ali Al Mukaimi Ahmed Mokhtar Mohamed Abo El Nass \\ Al Razi Orthopedic Hospital, Kuwait City, Kuwait
}

\section{Key Words}

Humeral shaft fracture $\cdot$ Nonunion · Locked nails ·

Delayed union

\begin{abstract}
Objectives: To assess the results and clinical outcome of delayed union and nonunion humeral shaft treatment using locked medullary nails. Subjects and Methods: The Russel and Taylor humeral locking nail was used to treat 21 patients with humeral shaft fractures at Al Razi hospital, Kuwait, from 1997 to 2001. Of these, 8 had delayed union and 13 nonunion. Also, 13 had previous operative treatment, while 8 had nonoperative treatment. Antegrade nailing was done in all cases, and all nails were fixed statically. Autogenous iliac bone grafts were used in 17 cases. Results: Of the 21 cases of fractures, 19 were united. Only 2 cases had persistent nonunion. Eighteen cases had satisfactory shoulder function, and 3 lost shoulder abduction between 40 and 65 degrees. Conclusion: Our data showed that humeral locked nails can achieve satisfactory clinical results in treating humeral shaft delayed unions and nonunions.
\end{abstract}

Copyright (C) 2005 S. Karger AG, Basel

\section{Introduction}

Humeral shaft fractures have traditionally been regarded as relatively benign with a high percentage of primary healing $[1,2]$. However, despite operative or nonoperative means of treatment, certain humeral shaft fractures are slow to heal and, some even fail to heal [1-3]. Surgery, the most frequent method of treatment for these difficult problems, continues to be fraught with complications $[3,4]$.

Various operative treatments of humeral delayed unions or nonunions have been reported with different success rates and complications [1-7]. Compression plating, with its high union rate and good functional recovery, has been the most common practice $[3,5,8]$. However, this procedure has the disadvantages of extensive soft-tissue dissection, unsightly scarring and risk of radial nerve injury $[6,9,10]$. Additionally, the rugged bone surface at the nonunion site also makes contouring of the plate more difficult [10]. For patients with osteoporosis, the screw on the bone is unreliable and prone to failure [9-11]. Moreover, among patients who need removal of the plate, operation on the severely adhered or scarred soft tissue surrounding the nerve carries an even higher risk of radial nerve injury and causes more healing problems [11].

$\begin{array}{ll}\text { KARGER } & \text { ( ) 2005 S. Karger AG, Basel } \\ \text { Fax +4161306 1234 } & \text { 1011-7571/05/0144-0245\$22.00/0 } \\ \begin{array}{l}\text { E-Mail karger@karger.ch } \\ \text { www.karger.com }\end{array} & \begin{array}{l}\text { Accessible online at: } \\ \text { www.karger.com/mpp }\end{array}\end{array}$


Compared with plating, intramedullary nailing has the advantage of less soft-tissue trauma and less postoperative infection $[7,8]$. It is particularly beneficial for acute fractures or nonunions that are associated with osteoporosis or bone comminution $[7,11]$ and for patients requiring walking with crutch [6]. However, unlocked nailing is complicated by poor rotational control of nails $[1,2,12]$; it can be an alternative for certain selected-delayed unions, but is not recommended for nonunions [8]. Locked nails which have the advantage of rotational stability have been used for treating humeral delayed unions and nonunions with varying degrees of success $[4,6]$. There has been much concern about the shoulder function [12, 13].

In this study, we report our experience of using the Russel and Taylor humeral locking nail in the treatment of delayed union and nonunion humeral fractures.

\section{Subjects and Methods}

The Russel and Taylor humeral locking nail was used to treat 21 patients with delayed union and nonunited humeral shaft fractures at Al-Razi Orthopedic Hospital in Kuwait between 1997 and 2001. Of the 21 patients, 15 were males and 6 females, with a mean age of 42.2 years (range 21-62). Eight had delayed union and 13 nonunion.

The inclusion criteria for the study were delayed and nonunited fractures located between $3 \mathrm{~cm}$ above olecranon fossa and $4 \mathrm{~cm}$ below the surgical neck. Three fractures occurred in the proximal third, 12 in the middle third and 6 in the distal third. Of these, 8 were open fractures, which were treated conservatively, while 13 had primary surgical fixations. Three fractures occurred in the proximal third, 12 in the middle third and 6 in the distal third. Eight cases had open fractures, while 13 had closed fractures. Of the 21 cases, 8 were treated conservatively, while 13 were treated surgically by 15 previous operations (two cases had surgeries twice). Operations included 9 plating, 2 rush pinning, 1 Kuntscher nailing and 1 external fixation. One patient had posttraumatic radical nerve palsy.

The average time between trauma and surgery was 4.3 months for delayed union (range 3-6 months) and 16.2 months for nonunion (range 7-25 months). Four cases had closed nailing, while 17 had open nailing with autogenous iliac bone grafting. The original operative wound was used in cases with previous plating, and radial nerve was exposed and protected. All cases were fixed by antegrade nailing through a small deltoid splitting approach.

The supraspinatus tendon was incised approximately $1 \mathrm{~cm}$ in length and carefully protected during operation. The Russel and Taylor nail is available in 3 different diameters: 7,8 and $9 \mathrm{~mm}$. It has a proximal locking screw, directed from lateral to medial direction and a distal locking screw directed anteroposteriorly. In all cases, reaming was done $1 \mathrm{~mm}$ larger than the nail to be used. The nail diameters used were $7 \mathrm{~mm}$ in 7 cases and $8 \mathrm{~mm}$ in 14 cases. All nails were inserted deep enough into the humeral head with utmost care to avoid any proximal protrusion. They were then fixed statically after ensuring maximal compression at the fracture site. Finally, the deltoid muscle and supraspinatus tendon were meticulously repaired.

Postoperatively, the arm was supported in the arm sling for 1 week. Range of motion exercise was encouraged as early as could be tolerated. Patients were allowed to use their operated arms for only light work 2-4 months postoperatively.

The patients were followed up clinically and by X-rays every 3 weeks up to 3 months then every 6 weeks until union was achieved.

The mean follow up period was 26.4 months (range 18-36 months). The range of motion of the shoulder joint was measured and compared with the contralateral side and with the preoperative range.

Clinical assessment was done using the criteria of Stewart and Hundley [14], where the range of shoulder movement is excellent if the loss does not exceed 15 degrees of shoulder abduction/forward flexion; good if the loss is between 16-35 degrees; fair if the loss is between 36-70 degrees, and poor if the loss is more than 70 degrees.

\section{Results}

Of the 21 cases, 19 (90.5\%) achieved eventual union, as exemplified in figures 1 and 2, which depict nonunion fractures after several months of plating (fig. 1) and rush pinning (fig. 2) that united. The mean time to union was 6.7 months, ranging from 3-12 months. In the two cases with nonunion, the fracture was in the distal third; one had infection; surgical cleaning was done twice and systemic antibiotics given, but eventually the patient developed infective nonunion and nail loosening (fig. 3). The second case involved a 35-year-old man who was lost to follow up, but then reappeared after 12 months with atrophic nonunion. The patient was treated by reinsertion of distal locking screw after compression at the fractured site without nail exchange, in addition to regrafting. However, union could not be achieved and the case was reported as a failure of the procedure.

In this study, 14 patients had loss of shoulder abduction less than 15 degrees; 4 up to 25 degrees; 2 up to 40 degrees and one 65 degrees of shoulder abduction. We had 18 cases $(85.7 \%)$ with either excellent or good results regarding shoulder function and 3 cases $(14.3 \%)$ with a fair range of shoulder movement.

Postoperative complications included: temporary radial nerve palsy ( 2 cases) and variable degrees of shoulder pain (3 cases). All were managed with analgesics and physical therapy. One case had delayed deep infection. We had no implant failure or nail migration. 
Fig. 1. A 37-year-old male with nonunited fracture 8 months after plate osteosynthesis that united 5 months after locked nailing.
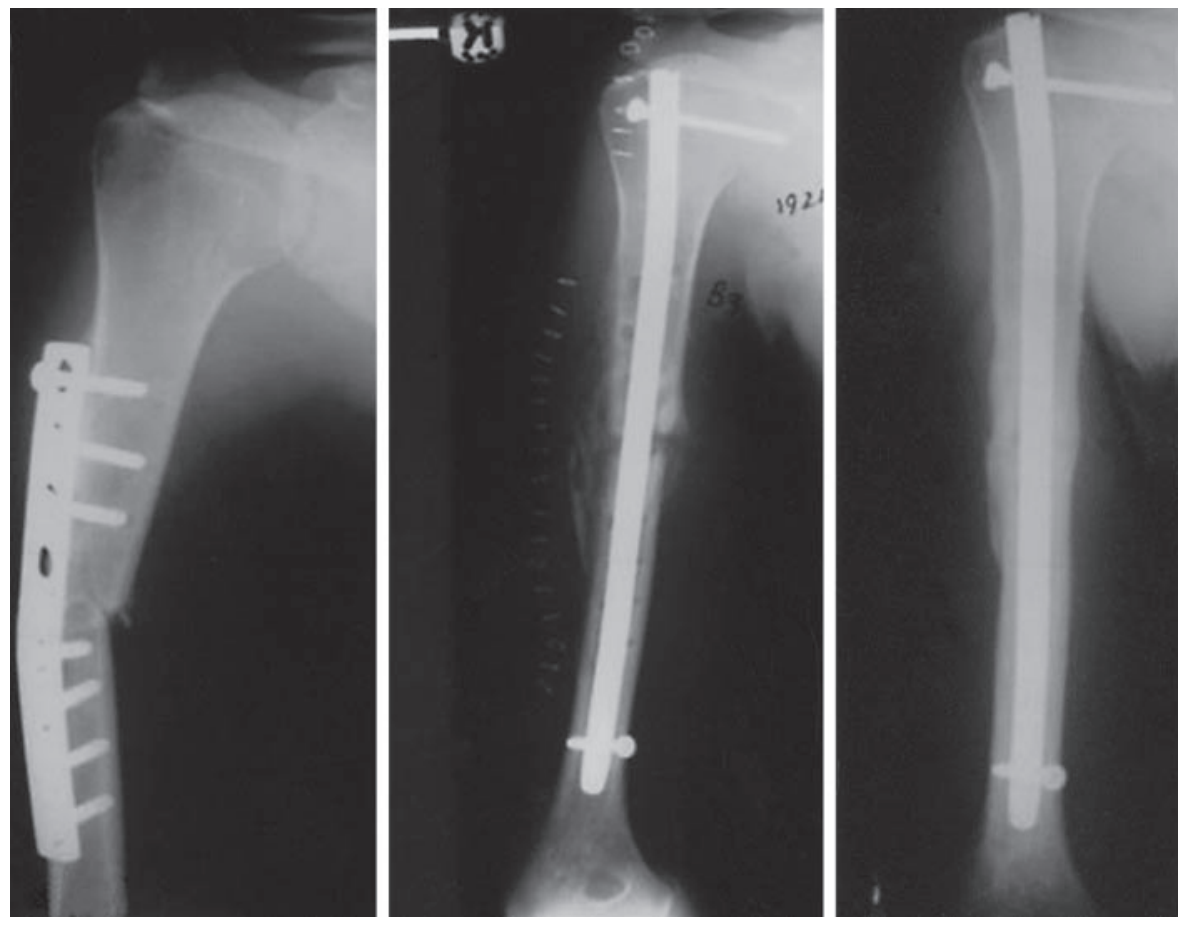

Fig. 2. A 30-year-old male with nonunited fracture 7 months after rush pinning, that united 8 months after closed locking nailing.
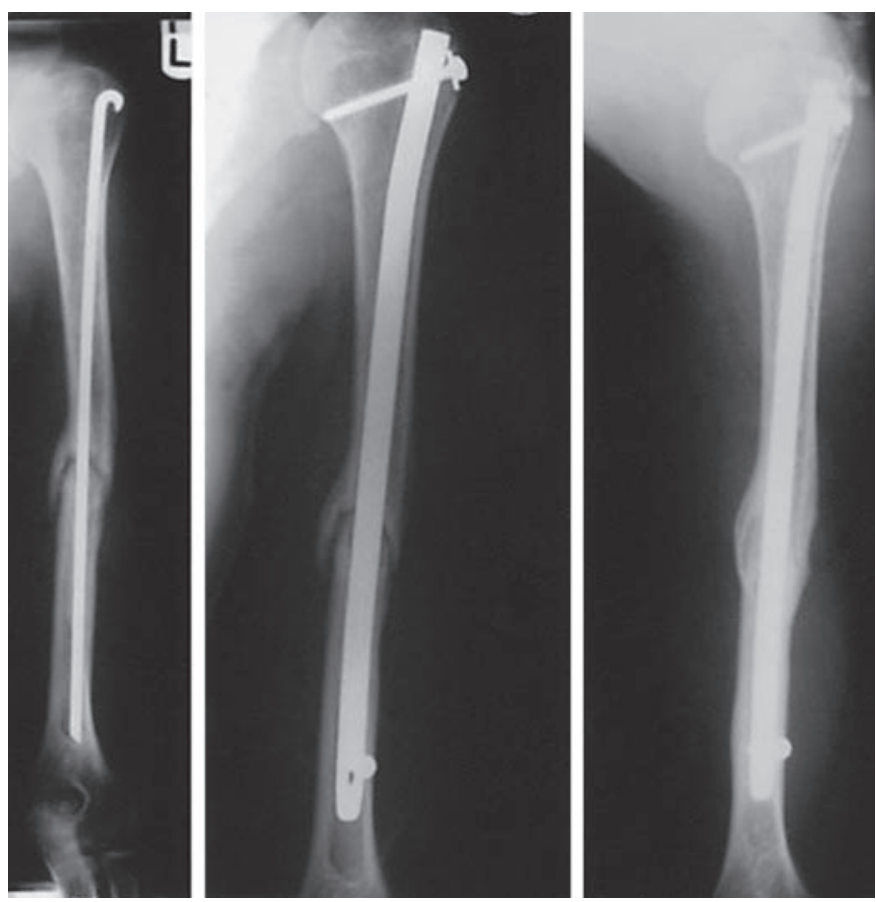

\section{Discussion}

The $90.5 \%$ eventual union achieved in this study gave excellent and good shoulder function, and is similar to that of previous studies involving acute $[6,7,11]$ and pathological fractures $[7,13,15]$. Humeral locks provide rotational control and prevent backing out of the nail. Hence, they are the preferred mode of treatment, particularly in situations where avascularity was caused by the previously failed osteosynthesis $[6,7,9,16]$. Com- 
Fig. 3. A 39-year-old male patient with nonunited fracture distal humerus 7 months after plating that became infective nonunion with nail loosening 6 months after locked nailing.
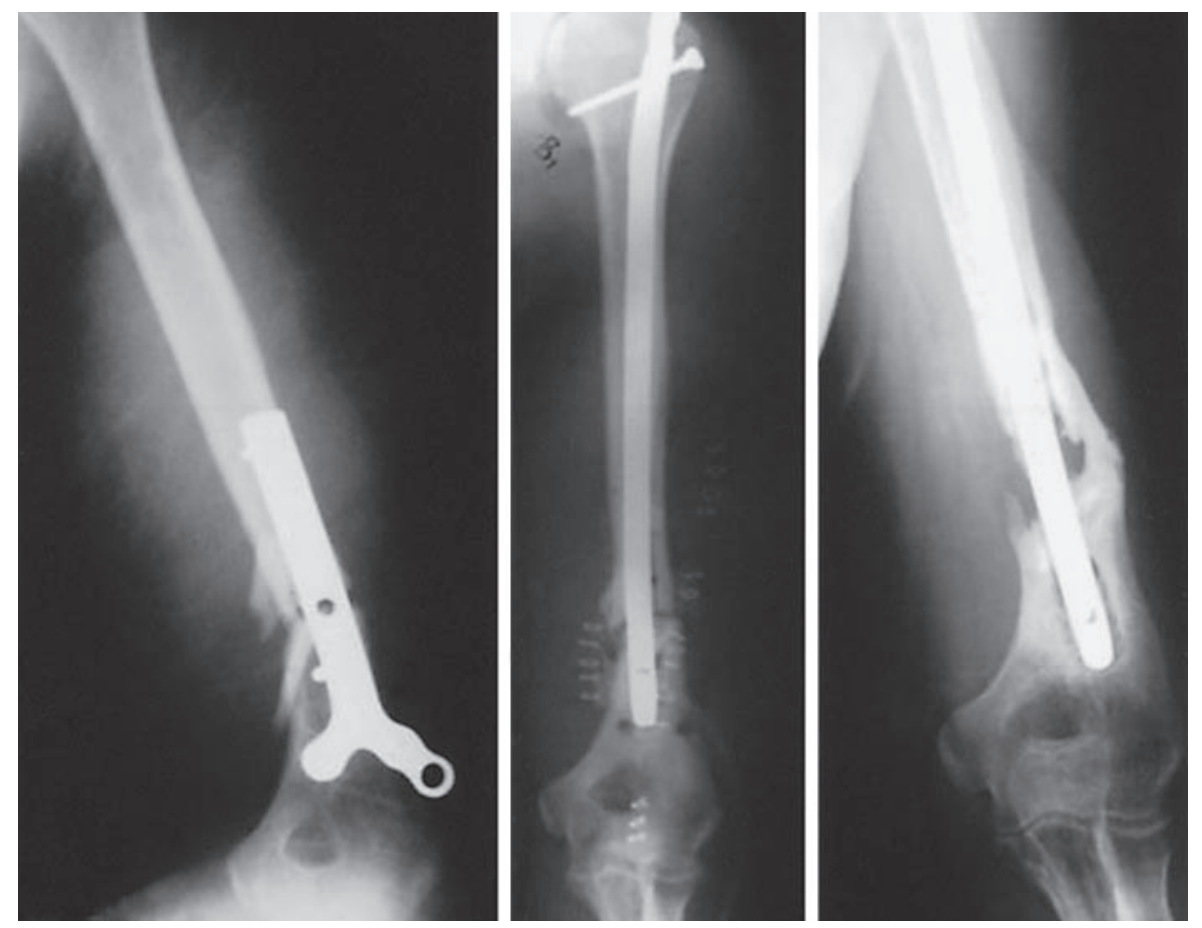

pared to plating, humeral locked nails cause less tissue trauma and circulatory impairment $[7,8]$. Plating could also cause radial nerve injury resulting in inadequate fixation of the fracture [5]. Equally, removal of nails and screws after fracture healing is easier and safer than removal of plates [11].

The failed two cases of this study involved fractures of the distal third. Using cadaveric humeri, Lin et al. [17] have shown that inferior fixation rigidity in antegrade nailing of distal fractures should include antegrade nailing for proximal fractures and retrograde nailing for distal fractures. Unfortunately, the Russell and Taylor nail has only one locking screw at both ends, so unless the fracture is properly impacted, there would be movement pivoting around the anteroposterior distal locking screw.

Impairment of shoulder function has been a major concern about antegrade nailing [12, 13]. Riemer [16] has shown that antegrade nailing itself is not the most likely factor that jeopardizes ultimate shoulder function. The other factor in the cases of delayed union or nonunion is that the patients had some degree of preoperative joint stiffness caused by long-term immobilization or previous surgeries as in our cases. Therefore, recovery of joint motion would be longer than usual. Deep insertion of the nail into the humeral head and minimizing surgical trauma of the soft tissue and bone are essential to decrease the functional impairment of the shoulder joint as reported by Lin [11].

\section{Conclusion}

Our study shows that the humeral locked nail can achieve satisfactory clinical results of humeral shaft delayed unions and nonunions. This nail offers the advantages of good stability for immediate postoperative joint exercise and minimal soft tissue trauma. It is an acceptable alternative for fractures unsuited for plate fixation, such as those with comminution, osteoporosis or severely adherent radial nerve. 


\section{References}

1 Christensen NO: Kuntscher intramedullary reaming and nail fixation for non-union of the humerus. Clin Orthop 1976;116:222-226.

$>2$ Foster RJ, Dixon GL, Bach AW, Appleyard RW, Green TM: Internal fixation of fractures and non-unions of the humeral shaft. J Bone Joint Surg Am 1985;67:857-864.

$>3$ Healy W, White GM, Mick CA, Brooker AF, Weiland AJ: Non-union of the humeral shaft. Clin Orthop 1987;219:206-213.

$\checkmark 4$ McKee MD, Miranda MA, Riemer BL: Management of humeral non-union after the failure of locking intramedullary nails. J Orthop Trauma 1996;10:492-499.

$\checkmark 5$ Esterhai JL, Brighton CT, Heppenstall RB, Thrower A: Non-union of the humerus. Clin Orthop 1986;211:228-234.

-6 Ingman AM, Waters DA: Locked intramedullary nailing of humeral shaft fractures. J Bone Joint Surg Br 1994;76:23-29.
$>7$ Lin J, Hou SM, Hang YS, Chao EYS: Treatment of humeral shaft fractures by retrograde nailing. Clin Orthop 1997;342:147-155.

$>8$ Rosen H: The treatment of non-unions and pseudarthroses of the humeral shaft. Orthop Clin North Am 1990;21:725-742.

-9 Wu CC: Humeral shaft non-union treated by a Seidel interlocking nail with a supplementary staple. Clin Orthop 1996;326:203-208.

10 Wu CC, Shih CH: Treatment for nonunion of the shaft of the humerus: Comparison of plates and Seidel interlocking nails. Can J Surg 1992; 35:661-665.

$>11$ Lin J: Treatment of humeral shaft fractures with humeral locked nail and comparison with plate fixation. J Trauma 1998;44:859-864.

12 Brumback RJ: The rationales of interlocking nailing of femur, tibia and humerus. Clin Orthop 1996;324:292-320.
13 Flinkkila T, Ristiniemi J, Hamalainen M: Non-union after intramedullary nailing of humeral shaft fractures. J Trauma 2001;50:540544.

14 Stewart MJ, Hundley JM: Fractures of the humerus, a comparative study in methods of treatment. J Bone Joint Surg 1955;37A:681692.

15 Redmond BJ, Bierman JS, Blasier RB, Michigan A: Interlocking intramedullary nailing of pathological fractures of the shaft of the humerus. J Bone Joint Surg Am 1996;78:891896.

16 Riemer BL: Intramedullary nailing of the humerus; in Browner BD (ed): The Science and Practice of Intramedullary Nailing. Baltimore, Williams \& Wilkins, 1996, pp 241-263.

17 Lin J, Inoue N, Valdevit A, Hang YS, Hou SM, Chao EYS: Biomechanical comparison of antegrade and retrograde nailing of humeral shaft fractures. Clin Orthop 1998;351:203-213. 